\title{
Adaptation of Oral Hygiene Habits in Dental Professionals: A Kap Study
}

\section{Hanan William, ${ }^{1}$ Deema Munir, ${ }^{2}$ Rabia Arshad, ${ }^{3}$ Shazel William ${ }^{4}$}

\begin{abstract}
Objective: The present survey was carried out to assess the practice and perception of dental professionals towards their own dental care.

Methods: This cross-sectional study was carried from May 2019 to April 2020, in Altamash Institute of Dental Medicine, Karachi. Ethical approval was obtained from institutional review board. A selfadministered questionnaire was developed comprising of 20 questions among the dental personnel (Staff and BDS students) of Altamash Institute of Dental Medicine Karachi, Pakistan, to assess their practice and care, regarding their own oral hygiene. Responses were collected through both, the hard copy and an online google form link. Data was evaluated for 176 complete forms. For all the asked questions, a comparison was also made between male and female candidates, and between their academic levels. For all the variable as categorical values, percentages were tabulated using SPSS 21.

Results: The results indicated that not all the dental professionals had their same practice to maintain oral hygiene. Not all of them were following the proper theoretical knowledge. From their choices of toothpastes to their habits of flossing and using additional aids for maintaining oral hygiene, majority factors varied individually in spite of the fact that there is well-awareness of consequences of negligence.

Conclusion: It was found that not all the dental practitioners follow the proper guidelines to maintain oral hygiene, and not all of them follow the instructions they give to their patients.

Key Words: Oral Hygiene, Dental Professionals, Tooth Paste, Mouth Wash, Dentistry, Oral Hygiene Maintenance, Dental practitioners.
\end{abstract}

\section{Introduction}

$\mathrm{T}$ he negative effects of abysmal oral health conditions on health and quality of life, cannot be ignored. ${ }^{1}$ There can be multiple consequences of poor oral hygiene, the most common of which is bad odor from mouth or Halitosis. Poor oral hygiene can be a major cause for it, which includes, dental plaque and caries, gingivitis, periodontitis, malignancies, dry mouth on the other hand may or may not be a contributing factor. ${ }^{2-6}$ The purpose of dentistry is to respond to the patients need and desires so as to restore the

\footnotetext{
1. Hanan William

3. Rabia Arshad

2. Deema Munir

4. Shazel William

1,2 Deptt. of Dental Medicine, Altamsh Institute of Dental Medicine

3. Department of Pharmacology, AIDM

4. Department of Community Dentistry, AIDM
}

\section{Correspondence:}

Dr. Rabia Arshad

Head and Associate Professor, Department of Pharmacology, AIDM,

Email:rabs78@gmail.com

Submission Date: 1st Revision Date: Acceptance Date: patient's oral health to normal contour, function, comfort, esthetics \& speech. ${ }^{7,8}$ Dentists with proper knowledge and oral health methods can contribute to the oral education and act as role models for the general community.' For transferring proper knowledge and awareness to the patient, a dental practitioner should first practice himself on all the suggestions before he advises to patients.

Due to professional knowledge of the prevention of oral diseases, dentists hold a key position in providing a positive role for oral self-care and to instruct and encourage their patients to maintain good oral health behavior. ${ }^{10}$

It was hypothesized that dentists with better orientation and greater knowledge of preventive care would have better oral hygiene behavior and dental service utilization. When talking about the preventive orientation in dentistry, it is determined by the statement that "Preventive training and practice should be increased both in undergraduate education and in dental practice". " Education contributes to improve 
knowledge, and as a level of education increases there is improvement in the level of oral health, awareness, attitude and behavior. ${ }^{12}$

Dentistry as a profession is known to be stressful both physically and mentally thus demanding more responsibility by dentists for their own general and oral health well-being. ${ }^{10}$ Health related knowledge, attitudes and beliefs acquired through professional education could therefore be the most significant individual level factors influencing their intermediate and final oral health outcome. In any society, dental professional should thus be a model group regarding oral health. ${ }^{11}$

Thus, the present study was designed and executed among dental practitioners in a dental institute to assess their own oral hygiene awareness, practice and maintenance, with the main objective that whether they put the same efforts in maintaining their oral health or not as they advise their patients.

\section{Methods}

The current cross-sectional study was conducted with informed consent, from March 2019 to February 2020. Ethical approval was obtained from institutional review board. A self-administered questionnaire was developed comprising of 20 questions among the dental personnel of Altamash Institute of Dental Medicine Karachi, Pakistan, to assess their practice and care, regarding their own oral hygiene. Responses were collected through both, the hard copy and an online google form link. Around 200 questionnaires were distributed to get the responses and data was evaluated for 176 completed forms with appropriate answers.

STATISTICS: The statistical analysis was done through SPSS version 21. Descriptive analysis was done and Percentages were calculated for all the variables. Chi-square was applied for all the question for comparison between male and females, and also for academic qualifications. The p-value of 0.05 or less was considered significant.

\section{Results:}

The total number of dental personnel targeted were 200 , out of which $36.9 \%$ males and $18-24$ year. For age $60.2 \%$ patients were in 18-24-year age limit, 32.4
$\%$ patients were 25-34 year age group whereas 7.4\% patients were above 34 year of age. For academic levels, $40.3 \%$ patients were undergrads, $44.3 \%$ patients were graduates whereas $15.3 \%$ are post graduate. Married patients were $15.9 \%$ whereas unmarried were $84.1 \%$. $65.3 \%$ were the ones who brush twice a day as per recommended by American Dental Asso-ciation. Only 36.4\% said that they brush their teeth before going to bed and after breakfast. Among all the participants, $56.3 \%$ brush their teeth for a recommen-ded time of 2 mins and $62.5 \%$ used soft tooth brushes. $95.5 \%$ of the candidates used tooth brush and toothpaste to maintain their oral hygiene, among which $75 \%$ used fluoridated tooth pastes. $25 \%$ were the ones who used pea sized quantity of toothpaste. $50.6 \%$ used mouth wash and $26.1 \%$ used dental floss as an additional aid to clean their teeth. It concludes that $43.2 \%$ dental professionals were aware of the right time to change their toothbrush and $40.3 \%$ of the dental professionals practice the correct method of brushing. To remove the food debris from the teeth $46.6 \%$ of our participants used dental floss.

It was indicated that, $80.7 \%$ of the participants believed that oral health is overall health. Taking para-functional habits into view, $20.5 \%$ said that they possess para-functional habits, $59.7 \%$ said that they do not and $8.5 \%$ quit. $34.7 \%$ complained of bleeding gums occasionally, $5.7 \%$ had bleeding gums while brushing and 52.8\% never experienced bleeding gums. $60.8 \%$ dental professionals did not have halitosis at all, $27.8 \%$ had it occasionally whereas $3.4 \%$ had it always.

Considering the eating and drinking habits of our participants, $45.5 \%$ were the one who ate sweet products anytime of the day whereas $35.8 \%$ had them once a week. $48.9 \%$ were the ones who had carbonated drinks once a week and $29.5 \%$ had them anytime of the day. $25.6 \%$ get their teeth professionally cleaned every 6 months and $40.3 \%$ get them cleaned once a year. $60 \%$ dentists claimed that they take care of their own oral hygiene as they instruct their patients and $11.4 \%$ did not take care in the same way. As shown in Table No.1

When comparison was made between the male and female and and for the academic levels, all the variables wither showed non-significant results or chi-square test was not applicable due to decrease 
cell count. As shown in Table No. 2

\section{Discussion}

Today, it is well-known that abysmal oral health conditions have a negative effect on overall health and quality of life in people. ${ }^{3}$ The purpose of dentistry is to respond to the patients' needs and desires i.e. to restore the patient's oral health to normal contour, function, comfort, esthetics \& speech. ${ }^{9,10}$ Oral hygiene is the practice of keeping the mouth clean by brushing and flossing to halt tooth and gum diseases. Good oral hygiene has shown to contribute immensely to the prevention of oral diseases. ${ }^{15}$
According to our research carried out among the dental professionals, $65.3 \%$ of the participants were the ones who brushed twice daily. Similar results were found out in a research carried out in 2002 by. Merchant et al, which demonstrated that $70 \%$ of the participants brushed twice daily. ${ }^{16}$ In a study carried out among the Mongolian dentists in 2004, it was concluded that $81 \%$ of the practitioners brushed twice a day and $62 \%$ used fluoridated toothpastes whereas in our study the fluorinated tooth paste utilization is $75 \%{ }^{13}$

Another study by. Gopinath in 2010 showed that, $55.9 \%$ respondents brushed twice a day and $55.1 \%$ of the practitioners used fluoridated toothpastes and

Table 1: Participants Characteristics and Oral Hhygiene Details $(N=176)$

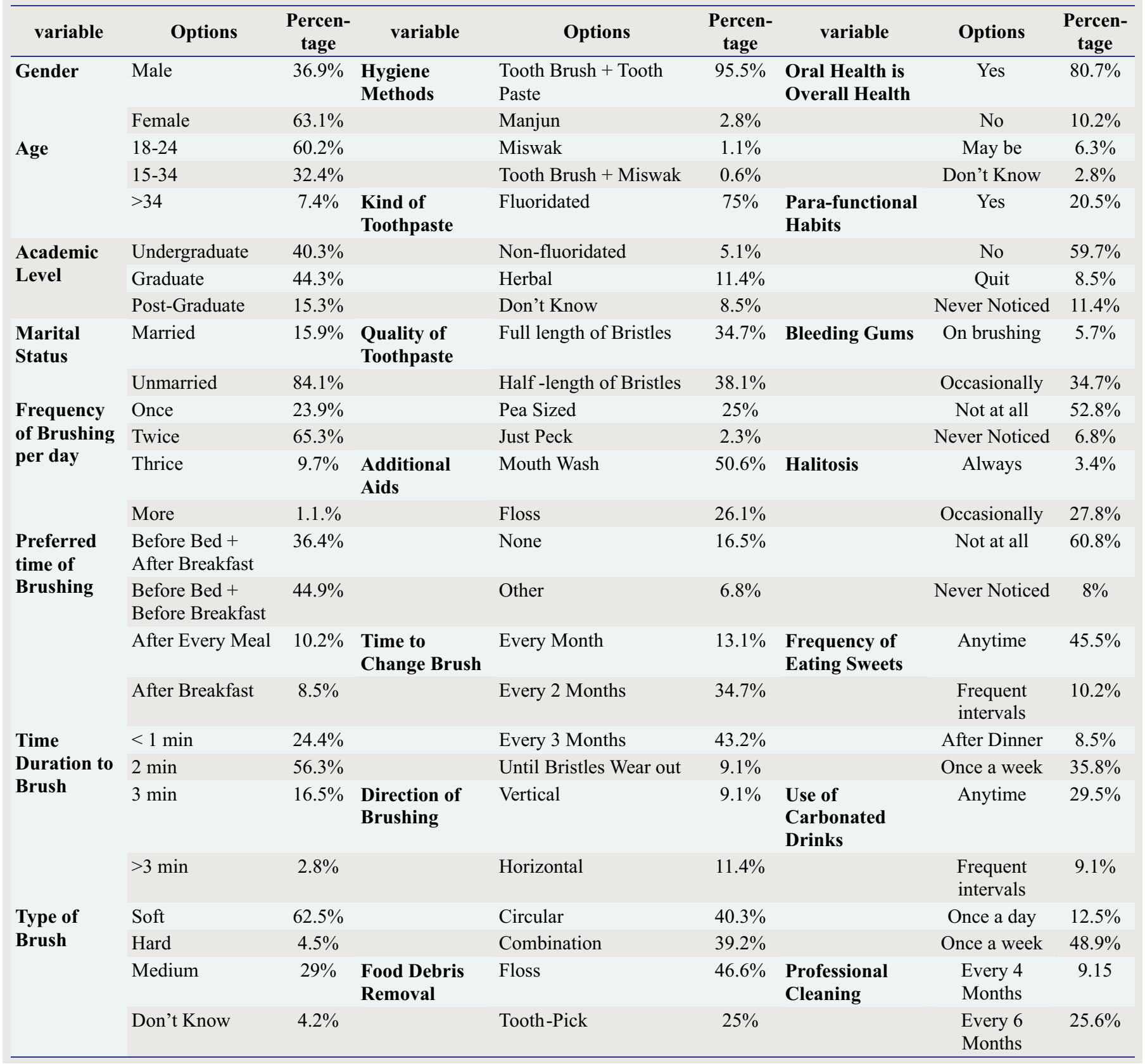


$19.6 \%$ followed the recommended instructions to maintain oral hygiene, whereas in our research, $75 \%$ people used fluoridated toothpastes and $60.2 \%$ followed the recommended instructions. ${ }^{17}$

Mechanical methods of plaque control e.g. the effec-

Table 2: Comparison of Male and Female and Academic Levels for all the Variables $(N=176)$

\begin{tabular}{|c|c|c|c|c|c|c|c|c|}
\hline $\begin{array}{l}\text { Toothpaste and } \\
\text { Brushing Details }\end{array}$ & Options & $\begin{array}{l}\text { Male } \\
\mathrm{n}=66\end{array}$ & $\begin{array}{c}\text { Female } \\
n=110\end{array}$ & p-value & $\begin{array}{c}\text { U/grad } \\
n=71\end{array}$ & $\begin{array}{l}\text { Grad } \\
\mathrm{n}=78\end{array}$ & $\begin{array}{c}\text { Post/grad } \\
\mathbf{n}=27\end{array}$ & $\begin{array}{c}\text { p- } \\
\text { value }\end{array}$ \\
\hline \multirow{4}{*}{$\begin{array}{l}\text { Frequency of } \\
\text { brushing }\end{array}$} & Once & 23 & 19 & NA & 14 & 18 & 10 & NA \\
\hline & Twice & 33 & 82 & & 52 & 51 & 12 & \\
\hline & Thrice & 8 & 9 & & 5 & 8 & 4 & \\
\hline & More & 2 & 0 & & 0 & 1 & 1 & \\
\hline \multirow{4}{*}{$\begin{array}{l}\text { Preferred Time to } \\
\text { Brush }\end{array}$} & Before Bed + After Breakfast & 22 & 42 & 0.54 & 26 & 29 & 9 & NA \\
\hline & Before Bed + Before Breakfast & 28 & 51 & & 35 & 33 & 11 & \\
\hline & After Every Meal & 9 & 9 & & 4 & 11 & 3 & \\
\hline & After Breakfast & 7 & 8 & & 6 & 5 & 4 & \\
\hline \multirow{4}{*}{$\begin{array}{l}\text { Time Duration to } \\
\text { Brush }\end{array}$} & $<1 \min$ & 9 & 34 & NA & 19 & 17 & 7 & NA \\
\hline & $2 \min$ & 47 & 52 & & 45 & 41 & 13 & \\
\hline & $3 \mathrm{~min}$ & 9 & 20 & & 6 & 17 & 6 & \\
\hline & $>3 \mathrm{~min}$ & 1 & 4 & & 1 & 3 & 1 & \\
\hline \multirow[t]{4}{*}{ Type of Toothbrush } & Soft & 40 & 70 & NA & 50 & 47 & 13 & NA \\
\hline & Hard & 2 & 6 & & 3 & 4 & 1 & \\
\hline & Medium & 20 & 31 & & 16 & 24 & 11 & \\
\hline & Don't know & 4 & 3 & & 2 & 3 & 2 & \\
\hline \multirow[t]{4}{*}{ Kind of Toothpaste } & Fluoridated & 48 & 84 & NA & 54 & 58 & 20 & NA \\
\hline & Non-fluoridated & 2 & 7 & & 2 & 5 & 2 & \\
\hline & Herbal & 10 & 10 & & 9 & 8 & 3 & \\
\hline & Don’t Know & 6 & 9 & & 6 & 7 & 2 & \\
\hline \multirow{4}{*}{$\begin{array}{l}\text { Quantity of } \\
\text { Toothpaste }\end{array}$} & Full length of Bristles & 24 & 37 & NA & 23 & 27 & 11 & NA \\
\hline & Half -length of Bristles & 23 & 44 & & 31 & 27 & 9 & \\
\hline & Pea Sized & 15 & 29 & & 17 & 23 & 4 & \\
\hline & Just Peck & 4 & 0 & & 0 & 1 & 3 & \\
\hline \multirow{4}{*}{$\begin{array}{l}\text { Time to Change } \\
\text { Brush }\end{array}$} & Every Month & 11 & 12 & 0.087 & 11 & 8 & 4 & NA \\
\hline & Every 2 Months & 20 & 41 & & 22 & 30 & 9 & \\
\hline & Every 3 Months & 25 & 51 & & 32 & 33 & 11 & \\
\hline & Until Bristles Wear out & 10 & 6 & & 6 & 7 & 3 & \\
\hline \multirow{4}{*}{$\begin{array}{l}\text { Direction of } \\
\text { Brushing }\end{array}$} & Vertical & 10 & 6 & 0.065 & 5 & 6 & 5 & NA \\
\hline & Horizontal & 10 & 10 & & 7 & 10 & 3 & \\
\hline & Circular & 25 & 46 & & 29 & 30 & 12 & \\
\hline & Combination & 21 & 48 & & 30 & 32 & 7 & \\
\hline \multirow{4}{*}{$\begin{array}{l}\text { Duration between } \\
\text { Meal and Brushing }\end{array}$} & $5 \mathrm{~min}$ & 6 & 9 & 0.086 & 7 & 5 & 3 & NA \\
\hline & $10 \mathrm{~min}$ & 14 & 17 & & 11 & 15 & 5 & \\
\hline & $15 \mathrm{~min}$ & 24 & 26 & & 20 & 23 & 7 & \\
\hline & I don't brush after meals & 22 & 58 & & 33 & 35 & 12 & \\
\hline \multirow{4}{*}{$\begin{array}{l}\text { Food Debris } \\
\text { Removal }\end{array}$} & Floss & 29 & 53 & NA & 30 & 43 & 9 & NA \\
\hline & Tooth-Pick & 15 & 29 & & 21 & 14 & 9 & \\
\hline & Nothing & 14 & 23 & & 14 & 16 & 7 & \\
\hline & Others & 8 & 5 & & 6 & 5 & 2 & \\
\hline \multirow[t]{4}{*}{ Hygiene Methods } & Tooth Brush + Tooth Paste & 59 & 109 & NA & 70 & 75 & 23 & NA \\
\hline & Manjun & 4 & 1 & & 1 & 1 & 3 & \\
\hline & Miswak & 2 & 0 & & 0 & 2 & 0 & \\
\hline & Tooth Brush + Miswak & 1 & 0 & & 0 & 0 & 1 & \\
\hline Additional Aids & Mouth Wash & 27 & 62 & NA & 35 & 36 & 18 & NA \\
\hline
\end{tabular}

Chi square test applied, * statistically significant difference, $\mathrm{NA}=$ chi square not applicable due to decreased cell count 
tive way of using a toothbrush and dental floss can aid oral health and decrease the incidence of dental discomforts and abnormalities. ${ }^{18-20}$ Comparing the genders, in a research carried out in 2019 showed that females were more active in flossing their teeth than men, just like our research showing females to be more proficient in taking extra steps for oral care. ${ }^{21} \mathrm{~A}$ research carried out in 2019 signified that $70 \%$ of their participants brushed their teeth only once a day, leading to dental issues. Our research had results in accordance to a study conducted in India in 2014, which stated that their participants had a habit of brushing two times a day. ${ }^{22,23}$

In a study carried out in Brazil and four Asian countries, it was concluded that majority of the candidates brushed once a day which was dissimilar to our study. ${ }^{24}$ Our research revealed that $45.5 \%$ of the practitioners could take sugar products anytime of the day unlike the members of the study in 2004, where $52 \%$ of the practitioners consumed sugar containing foods for less than once a day. ${ }^{13}$

Taking additional aids for oral hygiene into consideration, $50.6 \%$ and $26.1 \%$ of our practitioners used mouth wash and dental floss, whereas according to a study in 2002 by Merchant et al. 56.3\% of their participants used dental floss on a regular basis. ${ }^{16}$ Contrary to this, in a study in 2012 by Baseer et al, less than $50 \%$ of the candidates used dental floss and

Table 3: Comparison of Male and Female and Academic Levels for all the Variables (contd)

\begin{tabular}{|c|c|c|c|c|c|c|c|c|}
\hline Health and Habits & Options & $\begin{array}{l}\text { Male } \\
n=66\end{array}$ & $\begin{array}{c}\begin{array}{c}\text { Female } \\
n=110\end{array} \\
\text {. }\end{array}$ & $\begin{array}{c}\text { p- } \\
\text { value }\end{array}$ & $\begin{array}{c}\text { U/grad } \\
n=71\end{array}$ & $\begin{array}{l}\text { Grad } \\
n=78\end{array}$ & $\begin{array}{c}\text { Post/grad } \\
\mathbf{n}=27\end{array}$ & $\begin{array}{c}\text { p- } \\
\text { value }\end{array}$ \\
\hline \multirow{4}{*}{$\begin{array}{l}\text { Oral Health is Overall } \\
\text { Health }\end{array}$} & Yes & 52 & 90 & NA & 56 & 66 & 20 & NA \\
\hline & No & 8 & 10 & & 8 & 5 & 5 & \\
\hline & May be & 4 & 7 & & 6 & 5 & 0 & \\
\hline & Don’t Know & 2 & 3 & & 1 & 2 & 2 & \\
\hline \multirow[t]{4}{*}{ Bleeding from Gums } & On Every Brushing & 7 & 3 & NA & 4 & 2 & 4 & NA \\
\hline & Occasionally & 17 & 44 & & 26 & 26 & 9 & \\
\hline & Not at all & 35 & 58 & & 35 & 47 & 11 & \\
\hline & Never Noticed & 7 & 5 & & 6 & 3 & 3 & \\
\hline \multirow[t]{4}{*}{ Para-functional Habits } & Yes & 13 & 23 & 0.143 & 15 & 16 & 5 & NA \\
\hline & No & 34 & 71 & & 37 & 51 & 17 & \\
\hline & Quit & 8 & 7 & & 8 & 5 & 2 & \\
\hline & Never Noticed & 11 & 9 & & 11 & 6 & 3 & \\
\hline \multirow{4}{*}{ Halitosis } & Always & 4 & 2 & NA & 3 & 1 & 2 & NA \\
\hline & Occasionally & 18 & 31 & & 18 & 23 & 8 & \\
\hline & Not at all & 36 & 71 & & 46 & 48 & 13 & \\
\hline & Never Noticed & 8 & 6 & & 4 & 6 & 4 & \\
\hline \multirow{4}{*}{$\begin{array}{l}\text { Frequency of eating } \\
\text { sweets }\end{array}$} & Anytime & 34 & 46 & 0.600 & 37 & 31 & 12 & NA \\
\hline & Frequent Intervals & 5 & 13 & & 6 & 10 & 2 & \\
\hline & After Dinner & 5 & 10 & & 7 & 3 & 5 & \\
\hline & Once a week & 22 & 41 & & 21 & 34 & 8 & \\
\hline \multirow[t]{4}{*}{ Use of Carbonated Drinks } & Anytime & 22 & 30 & 0.341 & 23 & 16 & 13 & NA \\
\hline & Frequent Intervals & 6 & 10 & & 8 & 6 & 2 & \\
\hline & Once a day & 11 & 11 & & 10 & 8 & 4 & \\
\hline & Once a week & 27 & 59 & & 30 & 48 & 8 & \\
\hline \multirow[t]{4}{*}{ Professional Cleaning } & Every 4 Months & 8 & 8 & 0.374 & 6 & 3 & 7 & NA \\
\hline & Every 6 Months & 13 & 32 & & 19 & 23 & 3 & \\
\hline & Once a Year & 26 & 45 & & 24 & 34 & 13 & \\
\hline & Never & 19 & 25 & & 22 & 18 & 4 & \\
\hline \multirow[t]{4}{*}{ Oral Care as Instructed } & Yes & 41 & 65 & 0.174 & 38 & 51 & 17 & 0.650 \\
\hline & No & 9 & 11 & & 11 & 7 & 2 & \\
\hline & Occasionally & 11 & 31 & & 18 & 18 & 6 & \\
\hline & Never Noticed & 5 & 3 & & 4 & 2 & 2 & \\
\hline
\end{tabular}

Chi square test applied, * statistically significant difference, NA=chi square not applicable due to decreased cell count 
mouth wash and less than 10\% used Miswak and toothpick for their oral hygiene. ${ }^{25}$ In the same manner our research indicates least use of additional aids i.e. $1.1 \%$ of our candidates used Miswak and $0.6 \%$ used toothbrush + Miswak, though $25 \%$ were using toothpick as part of their routine oral hygiene.

A research published in 2008 concluded that $79.6 \%$ of their participants brushed twice out of which $73.8 \%$ brushed in circular motion. On the other hand, our survey showed that $40.3 \%$ were the ones brushing in circular motions. ${ }^{26}$ An analytical study in Saudi Arabia in 2020 declared that $57 \%$ of the women were doing brush in circular motion just like our study where majority of the women were doing the correct strokes of toothbrush. It's a well-known fact to use a brush with soft bristles for normal healthy teeth, 54\% of the male candidates for this study expressed that they used soft type of toothbrush, unlike the study we conducted where more females used soft type of tooth brushes. $^{27}$

Para-functional habit can be one of the major causes of poor oral conditions. A prevalence of these habits in a study in Rehman College of Dentistry, Peshawar, showed that $30 \%$ of the undergraduates had and $70 \%$ of them had no para-functional habits, similar to our survey where majority of the undergraduates had no such habits. ${ }^{28}$ Another research held 2017 in Lahore revealed that $38.3 \%$ of the undergraduates consumed carbonated drinks on daily basis, whereas $5.28 \%$ (10 out of 176) of the undergraduates in our study unveiled that they consumed carbonated drinks at least once a day. ${ }^{29}$

The current research we carried out clearly states that not all the dental professionals take proper measures to maintain a better oral hygiene, regardless the amount of knowledge they have through their theoretical and clinical experiences. This research was carried out on a limited number of candidates and in a limited environment. Further researches can be done on a vast majority of people giving more data about the title.

\section{Conclusion}

There is lack of practice towards oral hygiene maintenance by dental practitioners and it is found that not all of them follow proper guidelines and instructions as given to their patients. Further research would be needed for assessment. Also, there is need of improvement in practitioner's knowledge, behavior and attitude towards prevention to enable them to provide their patients and reinforce positive attitude for the same.

\section{Author's Contribution}

HW: Idea, Research Work

DM: Data Collection, write up

RA: Supervision, proof reading the manuscript

SW: Data evaluation, statistical work of study

\section{References}

1. Nagappa R, Reddy V P, Naidu T N, Vathare A S, Jadhav S S, Jadhav G K. Knowledge, attitude and practice of the dental and medical practitioners regarding dental implants. J International Oral Health. 2016;8(1):44.

2. Suprakash B, Ahammed AR, Thareja A, Kandaswamy R, Nilesh K, Bhondwe Mahajan S. Knowledge and attitude of patients toward dental implants as an option for replacement of missing teeth. J Contemp Dent Pract 2013;14(1):115-8.

3. Kandelman D, Petersen PE, Ueda H. Oral health, general health, and quality of life in older people. Spec Care Dentist 2008; 28: 224-236

4. Almas K, Al-Hawish A, Al-Khamis W. Oral hygiene practices, smoking habit, and self-perceived oral malodor among dental students. J Contemp Dent Pract. 2003;4(4):77-90.

5. Hine MK. Halitosis. J Am Dent Assoc. 1957; 55(1): 37-46.

6. Attia EL, Marshall KG. Halitosis. Can Med Assoc J. 1982; 126(11):1281-5.

7. McDowell JD, Kassebaum DK. Diagnosing and treating halitosis. J Am Dent Assoc. 1993;124(7): 5564.

8. Rosenberg M. Clinical assessment of bad breath: current concepts. J Am Dent Assoc. 1996 Apr;127(4): 475-82. Review. Erratum in: J Am Dent Assoc 1996; 127(5):570

9. Rathod V. Awareness about dental implants amongst dental practitioners in Navi Mumbai: a knowledge, attitude and practice study, International journal of recent scientific research 2018; 8(5):17013-17018

10. Tatum $\mathrm{OH}$. The Omni implant system. In Proceedings of the alabama implant congress, Birmingham, Ala 1988 May.

11. Suresh U, Ganesh A, Rajkumar M, Archana B, Balaji SK, Sangeetha H. Oral health knowledge and practices among school teachers in rural and urban areas of 
Chennai, Tamil Nadu: A questionnaire survey. J Indian Assoc Public Health Dentistry. 2019;17(1):80.

12. Ghasemi H, Murtomaa H, Vehkalahti M, Torabzadeh H. Determinants of oral health behaviour among Iranian dentists. International Dental Journal. 2007; 57:237-42.

13. Tseveenjav B, Vehkalahti M, Murtomaa H. Oral health and its determinants among Mongolian dentists. Acta Odontologica Scandinavica. 2004;62(1): $1-6$

14. Wagle M, Trovik TA, Basnet P, Acharya G. Do dentists have better oral health compared to general population: a study on oral health status and oral health behavior in Kathmandu, Nepal. BMC Oral Health. 2014; 14:23. doi:10.1186/1472-6831-14-23

15. Fotedar S, Fotedar V, Bhardwaj V, Thakur AS, Vashisth S, Thakur P Oral health knowledge and practices among primary healthcare workers in Shimla District, Himachal Pradesh, India. Indian J Dent Res 2018; 29:858-61.

16. Merchant A, Pitiphat W, Douglass CW, Crohin C, Joshipura K. Oral hygiene practices and periodontitis in health care professionals. J periodontology. 2002; 73(5): 531-5.

17. Gopinath V. Oral hygiene practices and habits among dental professionals in Chennai. Indian J Dental Research. 2010;21(2):195.

18. Singh MS, Tuli AK. A comparative evaluation of oral hygiene practices, oral health status, and behavior between graduate and post-graduate dentists of North India: An epidemiological survey. Journal of International Society of Preventive \& Community Dentistry. 2013;3(1):19.

19. Bardal PA, Olympio KP, Bastos MR, Henriques FC, Buzalaf RA. Education and motivation in oral health: Preventing disease and promoting health in patients undergoing orthodontic treatment. Dental Press J Orthod. 2011; 16:95-102

20. Choo A, Delac DM, Messer LB. Oral hygiene measures and promotion: Review and considerations. Aust Dent J. 2001; 46:166-73.
21. Lee A, Carver JC. FLOSS participants' perceptions about gender and inclusiveness: a survey. In2019 IEEE/ACM 41st International Conference on Software Engineering (ICSE) 2019 May 25 (pp. 677687). IEEE.

22. Almoteb MM, Alalyani SS, Gowdar IM, Penumatsa NV, Siddiqui MA, Sharanesha RB. Oral hygiene status and practices among health-care workers: A cross-sectional study. Journal of International Oral Health. 2019;11(5):268.

23. Reddy LR, Lavanya R, Saimadhavi N, Ramesh T, Jyothirmai K, Reddy PM, Saikiran C. Oral hygiene practices and habits among dental students and staff in a dental college, India. Cumhuriyet Dental Journal. 2014;17(1):7-13.

24. Frazão P, Marques D. Effectiveness of a community health worker program on oral health promotion. Revista de saudepublica. 2009; 43:463-71.

25. Baseer MA, Alenazy MS, AlAsqah M, AlGabbani M, Mehkari A. Oral health knowledge, attitude and practices among health professionals in King Fahad Medical City. Riyadh. Dental research journal. 2012; 9(4):386.

26. Ganss C, Schlueter N, Preiss S, Klimek J. Tooth brushing habits in uninstructed adults-frequency, technique, duration and force. Clinical oral investigations. $2009 ; 13(2): 203$.

27. Alsadiq RS, Alsihati AH, Elkholy NM, Takroni G, Uppin RB. Analytical Study to Assess People's Awareness of Toothbrush and Toothpaste Selection in Saudi Arabia. Donnish Journal of Dentistry and Oral Hygiene 2020; 6(4): 59-70

28. Khan MA, Mansur A, Amin M. Prevalence of Bruxism in Undergraduate Students, Clinical Staff and Patients at Rehman College of Dentistry. Pakistan Oral \& Dental Journal. 2019;39(2):218-21.

29. Shafi T, Aman Z. Knowledge Attitude \& Practices (KAP) Regarding Carbonated Drinks among female medical students of Allama Iqbal Medical College, Lahore. Proceeding SZPGMI 2017;31(2):92-7. 